\title{
Livelihood Vulnerability of Char Land Communities to Climate Change and Natural Hazards in Bangladesh: An Application of Livelihood Vulnerability Index
}

\section{Abdullah Al Mamun}

Begum Rokeya University

A R M Towfiqul Islam ( $\boldsymbol{\nabla}$ towfiq_dm@brur.ac.bd)

Begum Rokeya University https://orcid.org/0000-0001-5779-1382

GM Monirul Alam

Bangabandhu Sheikh Mujibur Rahman Agricultural University

Md. Nazirul Islam Sarker

Neijiang Normal University

Michael Odei Erdiaw-Kwasie

Charles Darwin University

Humnath Bhandari

International Rice Research Institute

Javed Mallick

King Khalid University

\section{Research Article}

Keywords: Charland, climate change, natural disaster, livelihood vulnerability, Bangladesh

Posted Date: January 10th, 2022

DOI: https://doi.org/10.21203/rs.3.rs-1238670/v1

License: (c) (i) This work is licensed under a Creative Commons Attribution 4.0 International License. Read Full License 


\title{
Livelihood Vulnerability of Char Land Communities to Climate Change and Natural
} Hazards in Bangladesh: An Application of Livelihood Vulnerability Index

\author{
Abdullah Al Mamun ${ }^{1}$, Abu Reza Md. Towfiqul Islam", G M Monirul Alam²*, Md Nazirul \\ Islam Sarker ${ }^{3}$, Michael Odei Erdiaw-Kwasie ${ }^{4}$, Humnath Bhandari ${ }^{5}$, Javed Mallick ${ }^{6 *}$ \\ ${ }^{1}$ Begum Rokeya University, Rangpur 5400, Bangladesh (mamundsm28@gmail.com). \\ ${ }^{2}$ Bangabandhu sheikh Mujibur Rahman Agricultural University, Dhaka \& University of Southern \\ Queensland, Australia (gmmonirul79@gmail.com) \\ ${ }^{3}$ Neijiang Normal University, Neijiang,China ( sarker@njtc.edu.cn) \\ ${ }^{4}$ Charles Darwin University, Australia (michael.erdiaw-kwasie@cdu.edu.au). \\ ${ }^{5}$ International Rice Research Institute, Dhaka, Bangladesh (h.bhandari@irri.org). \\ ${ }^{6}$ Department of Civil Engineering, King Khalid University, Abha, Saudi Arabia \\ (jmallick@kku.edu.sa)
}

"Corresponding author: towfiq_dm@brur.ac.bd; jmallick@kku.edu.sa; gmmonirul79@gmail.com

Abu Reza Md. Towfiqul Islam, PhD

G M Monirul Alam, PhD

Javed Mallick, PhD

ORCID: 0000-0001-5779-1382

Tel: $+880-2-58616687$

Fax: +880-2-58617946

\section{Abstract}

Bangladesh is one of the most vulnerable countries to climate change in the world. In general, Charland (Riverine Island) communities are frequently affected by floods, riverbank erosion, and other climatic hazards, which cause many to lose their sources of livelihoods and 
properties and making them more vulnerable. Using survey data of 262 rural households, this study investigates the extent of livelihood vulnerability to climate change and natural hazards of the Charland communities by applying the climate change vulnerability index (CVI) (i.e. UN-IPCC vulnerability framework) and the livelihood vulnerability index (LVI) to develop context-specific interventions for building climate and livelihood resilience. The two approaches of vulnerability assessment were modified to incorporate local contexts and indigenous knowledge into 41 sub-components. The result shows that LVI and CVI values are different between Charland communities. The LVI index shows that households in Char Jotindro-Narayan (0.148) are more vulnerable than Char Kulaghat (0.139). The CVI values for Char Jotindro-Narayan (0.633) are slightly lower than for Char Kulaghat (0.639). The major vulnerability factors were identified as the social networks, food self-sufficiency, natural disasters, and climatic variability. The study also indicates that flood, riverbank erosion, unemployment, and access to communication, market, and basic service opportunities are the major biophysical and socioeconomic factors determining livelihood vulnerability. The context-specific sustainable policies and development initiatives are required to improve the adaptive capacity of Charland communities across Bangladesh and thereby building their climate and livelihood resilience.

Keywords: Charland, climate change, natural disaster, livelihood vulnerability, Bangladesh

\section{Introduction}

Bangladesh is the world's most climate hot spot country due to its low-lying terrain and geographic condition and climate change over time (Alam, 2017; IPCC, 2014). It is thought that climate change aggravates similar hazardous incidents, including floods, riverbank erosion, drought, cyclone, water logging, etc., which adversely influences socioeconomic improvement and living communities (Alam, 2016; Simotwo et al., 2018; Panthi et al., 2016). In Bangladesh, these climatic hazards often occur on delta and riverine islands (huge 
sandbars that form in riverbeds as a result of silt and alluvium deposition) communities, specifically by the dynamic riverbank erosion and accumulation (Alam et al., 2017; Ahmed et al., 2019; Islam, 2018). These areas are known as char areas that are familiar with numerous natural hazards and socio-economic vulnerabilities. The impacts will differ for people who work in various occupations, e.g. agriculture, fisheries, business, etc. Every year, frequent riverbank erosion loses a great amount of agricultural and usable land of char communities (Alam, 2017). However, the communication structure of char land communities is also damaged by natural hazards that deny char residents equal opportunities to the economic and social benefits that mainland residents enjoy (Alam et al., 2017). These difficult scenarios are prevalent throughout Bangladesh's various char areas, which represent around $5 \%$ of the country's entire land (7200 sq. $\mathrm{km}$ ) and population (6.5 million people) (Alam, 2017; Alam et al., 2017; EGIS, 2000). The most challenging fact for the char land people is inability to relocate to the mainland to seek employment opportunities, which result in migrations within the char region (Alam et al., 2020).

A climate change model projection estimated that the mean yearly and seasonal temperature would be increasing until $4.7^{\circ} \mathrm{C}$ in our country by the end up of the century (Christensen et al., 2007). The precipitation in the wet season will be expected to increase by $11 \%$, while the winter arid time is expected to become notably thirstier; the rate and severity of cyclones in the Bay of Bengal are also expected to rise, leading to more heavy rainfall in coastline areas, culminating in extensive flooding and sea incursions (Christensen et al., 2007). Such challenges are damaging the livelihood and the landscape, providing the foundation for effective agricultural activities, such as cropping patterns, crop yields, insect infestations, and water availability. The households of char communities are frequently losing their agricultural products (e.g. yields, poultry, and livestock), as well as the human and financial 
assets required to conserve their financial prosperity and overall persistence (Alam et al., 2018).

Climate change vulnerability has been described by the degree to which a system or civilization is susceptible to, or at danger of, and incapable of dealing with the deleterious climate change impacts (Schneider, 2007). Vulnerabilities of climate and their related consequences differ depending on the communities' geographical, temporal, and socioeconomic characteristics (Alam, 2016; Ayanlade et al., 2018; Panthi et al., 2016). As a outcome, vulnerability assessment assists in determining a community's adaptability level, which is the first step in developing adaptive strategy initiatives to decrease the risks connected with climate change-induced disasters (Alam, 2017; Erdiaw-Kwasie et al., 2019; Zhang et al., 2018; Toufique and Islam, 2014; Vignieri, 2015). People in developing nations are vulnerable due to their reliance on farming and poor earnings (UNDP, 2008). These constraints can stimulate the investigation of resource-poor societies' possible adaptive capabilities (Nelson, 2007; Folke, 2006). The degree to which humans are vulnerable to natural hazards in nearly all aspects of living, such as the human, social, financial, physical and natural dimensions, has risen (Oo, 2018; Ford, 2010).

Investigating and analyzing vulnerability requires a context-specific approach at all regional levels to develop effective policy and strategy and minimize harmful consequences on livelihoods (Adger, 2005; Bevacqua, 2018). The relationship between individuals and their social and biophysical environments is easily utilized to evaluate the development-policy framework using particular indicators (Eriksen, 2007), and showing perspective adaptation strategies (Gbetibouo, 2010). It can compare and assess the level of vulnerability as it varies over time, location, and allocation of resources (Preston, 2011). The primary difficulty in vulnerability assessment is developing strong and reliable indicators (Adger, 2006). 
This study focuses on the char land region in Bangladesh. Geologically, Bangladesh is recognized as one of the world's biggest delta, which comprises about 230 rivers, encompassing three major rivers known as Ganges-Brahmaputra-Meghna (GBM), which contains massive inland bodies of water (Islam and Bhuiyan 2016, 2018; Monwar et al., 2018). In Bangladesh, coastline and riparian communities are the extremely vulnerable to the effects of climate induced hazards such as riverbank erosion, floods, cyclones, arsenic contamination, waterlogging, and salinity intrusion, etc. due to geographical context (Azad et al. 2013; Alam, 2016; Alam et al., 2017; Islam and Uddin, 2015; Islam 2013, 2014). Apart from the isolations suffered by char dwellers, the region is characterized by high precipitation rates that result in great riverbank erosion (around 150,000 square $\mathrm{km}$ ) over the past 10 years (Alam, 2017; Huq, 2008; Mutton, 2004). Over 20 of the 64 districts are vulnerable to severe riverbank erosion, subsequent in the loss of 8700 hectares of land and the relocation of approximately 200,000 people per year (Alam, 2016; Alam et al., 2017; Ahsan, 2014; Barrett, 2014; CEGIS, 2012; IFAD, 2011). Despite these threats and vulnerabilities, riverine peoples frequently choose char regions owing to increasing population pressure and cumulative stress on scarce land areas (BBS, 2014). The char land communities are recognized among the poorest and the most exposed group to environmental dangers (Alam, 2017; CLP, 2010; Islam and Hossain, 2013). Adding to this, char residents are faced with inadequate communication networks, which excludes them from the services and advantages available to 'mainland' residents (Sarker et al., 2020; Thompson, 2000).

For the government, NGOs, or/and foreign donor organizations to actively and successfully intervene in the current situations faced by the char residents, reliable information, and indepth study findings are required (IPCC, 2014; Islam, 2018; Alam, 2016; Alam et al., 2017). The policy action cannot occur unless the exact condition of char communities' vulnerability is understood (Alam et al., 2017; Sarker et al., 2020). The Bangladeshi government views the 
125 vulnerability of char households to be a critical issue that must be addressed (GOB, 2011).

126 This research intends to address this critical gap by implementing the IPCC vulnerability

127 approach and building a livelihood vulnerability index (LVI) and a climatic vulnerability 128 index (CVI). The study also seeks to investigate the range to which char communities are

129 vulnerable regarding livelihood and climate change situations within rural communities in the 130 char area of Bangladesh.

\section{Materials and methods}

\subsection{Study area}

133 The study was conducted at Phulbari Upazila in Kurigram and Lalmonirhat Sadar Upazila in 134 the Lalmonirhat district of northern Bangladesh. Geographically this area situated between $13525^{\circ} 52^{\prime} 0^{\prime \prime} \mathrm{N}$ to $25^{\circ} 58^{\prime} 0^{\prime \prime} \mathrm{N}$ latitude and $89^{\circ} 28^{\prime} 0^{\prime \prime} \mathrm{E}$ to $89^{\circ} 33^{\prime} 0^{\prime \prime} \mathrm{E}$ longitude (Fig.1). These regions are among the most vulnerable to natural hazards and considered as geographically remote riverine areas. The Dharla River crosses the study region, and poses lot of challenges including loss of livelihood assets, crops, and agricultural land, particularly in times of riverbank erosion. The regular flood and erosion of riverbank are a common phenomenon in the region that badly influence the char land communities (Mondal et al., 2020; Islam et al., 2019) (Figure 2). 


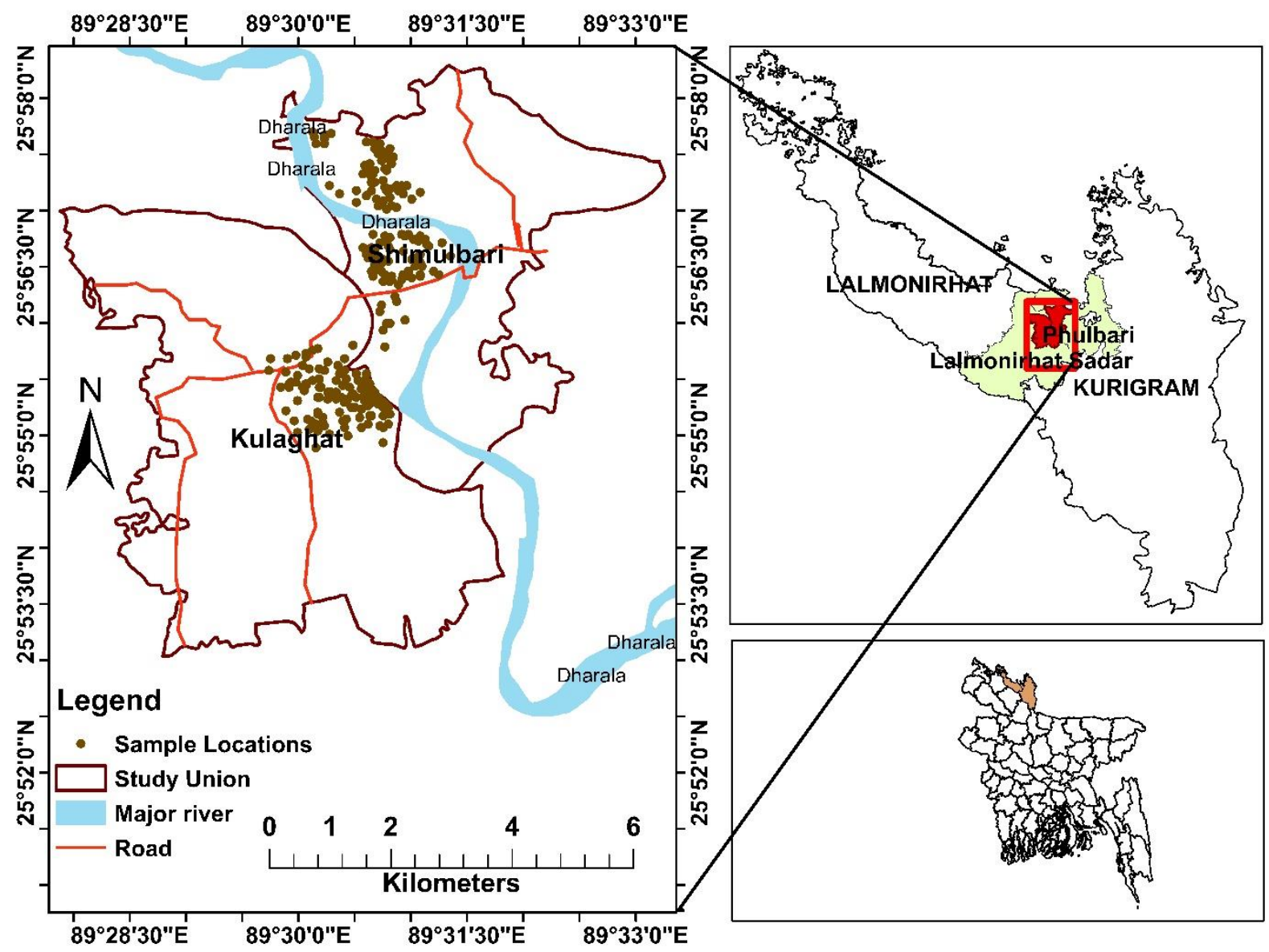

Fig. 1. Map presenting the location of the study region.

The study villages were purposively chosen based on the extent of their natural hazards especially flood and riverbank erosion, which has been reported by previous research papers, local expert views, policy documents, and newspapers. The respondents from these villages were elected randomly for the survey. The study determined on two main constituencies (i) the community which has relatively easy access to the mainland and (ii) the communities living in proximity to the Dharla River. Although both regions are frequently affected by natural hazards, they have their own uniqueness on the basis of communication system, education, health services, and different livelihood assets. The studied village in Phulbari Upazila was Char Jotindro-Narayan, and the distant villages in Lalmonirhat Sadar Upazila were Kulaghat char. 


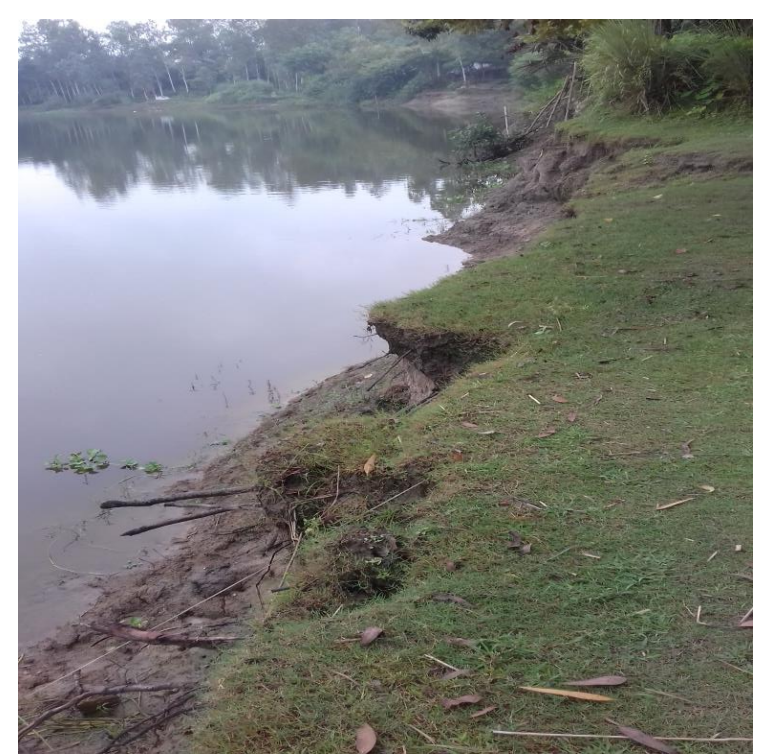

Riverbank erosion

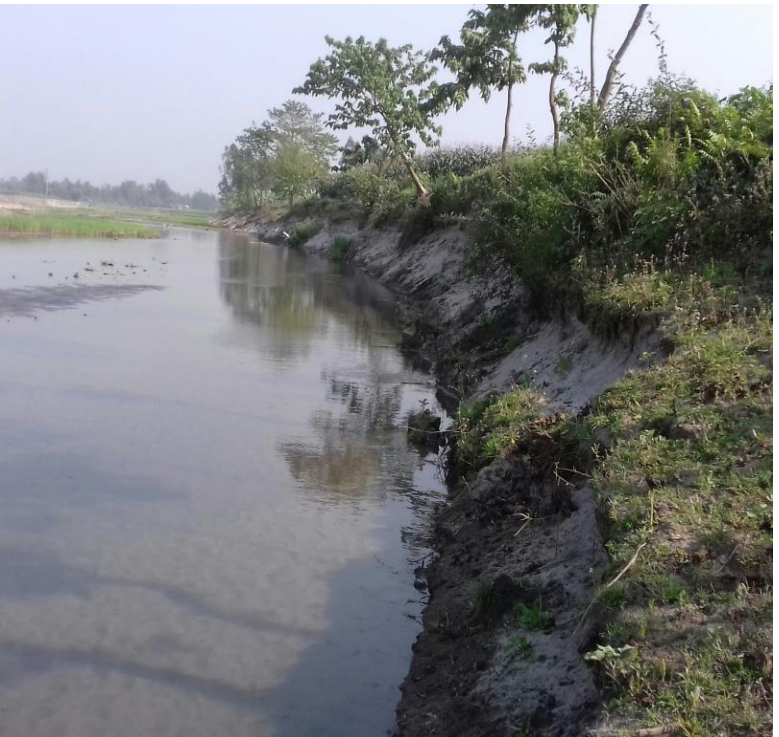

Riverbank area

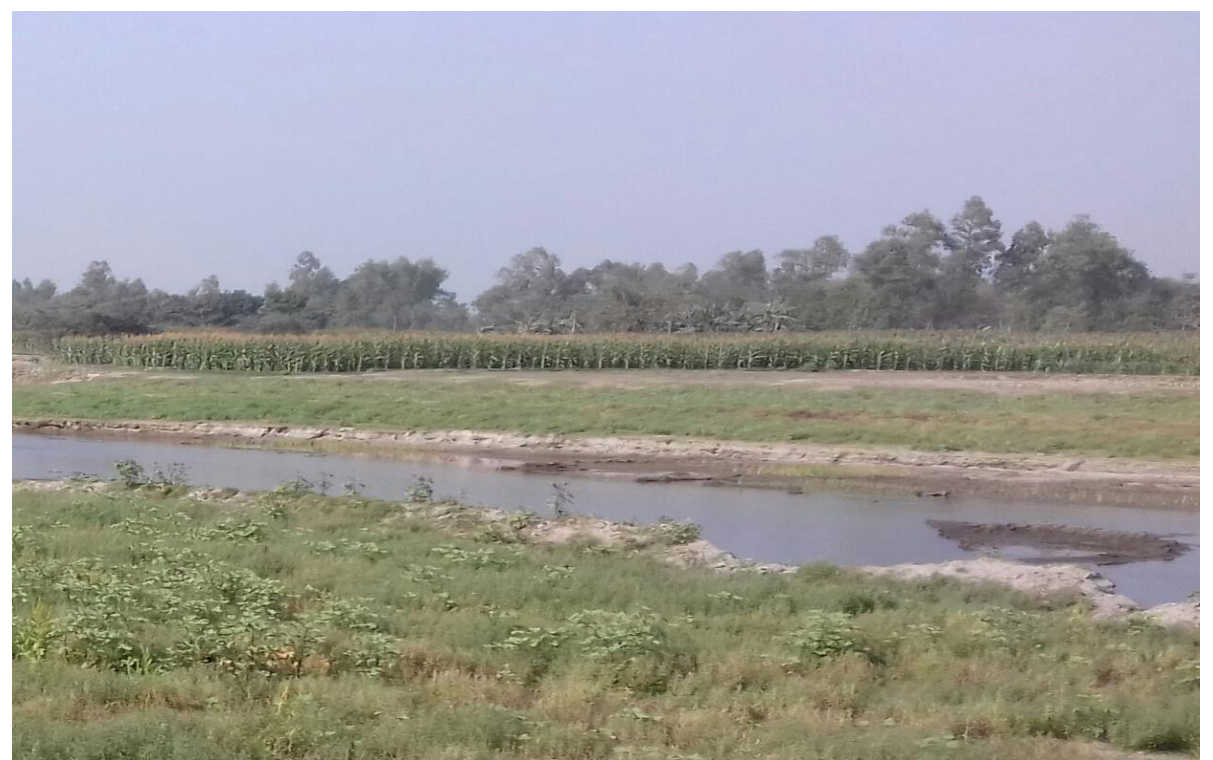

\section{Char land cultivation}

Fig. 2. Dharla river-bank erosion and livelihoods.

\subsection{Sample size estimation}

To estimate the sample size Cochrans formula (1977) was applied (Eq. 1). According to the BBS (2011), these two selected villages from Phulbari and Lalmonirhat Sadar Upazila were a total of 823 households. The apprised sample size was 262 (131 for Char Jotindro-Narayan in Phulbari Upazila and 131 for Kulaghat char in Lalmonirhat Sadar Upazila). The confidence level was 95\%, while the margin of error (confidence interval) was 5\%, respectively (Cochrans, 1977). 
Where,

\subsection{Questionnaire and data collection}

The survey was performed using a semi-structured questionnaire, focus group discussions pretest surveys were conducted to examine the transparency of the questionnaire, its appropriateness for contributors, the time required for per interview, and any potential impediments that could occur during the survey. After that, the questionnaire was finalized, consisting of three sections (i) adaptive capacity, (ii) exposure and, (iii) sensitivity, as well as eight major livelihood components. The household head was the main targeted respondent.

The survey was in the local language. A multi-stage sampling technique was used to identify respondent households. Moreover to surveys, two focus group discussions (FGDs) were conducted in each village by groups of 10-12 family heads to collect perspectives on various climatic and socioeconomic variables. These thoughts were subsequently utilized to cross certify the survey results. Questions involved in the survey questionnaire are defined as the major components in Table 1. Analysis of Livelihood vulnerability index (LVI) and Climate Vulnerability Index (CVI) values was obtained utilizing Microsoft Excel and SPSS 24.

\subsection{Context-specific framework approach}

187 Climate vulnerability refers to the extent to which environmental, geophysical, and socioeconomic conditions are susceptible and incapable to deal with the negative effects of climate change (IPCC, 2007). Climate vulnerability is a composite and sophisticated legislative issue, engaging with social, economic, political, and environmental elements at 
global, nationwide, and local levels (Adger, 2005; 2006). Climate vulnerabilities and their related impacts differ across sectors and contexts depending on the geographical, temporal, and socioeconomic characteristics (Alam, 2016; Ayanlade et al. 2018; Jurgilevich, 2017). The context-specific approach responds with knowledge of the complicated historical and contemporary context in which any action is being performed, as well as the potential influence and engagement that any activities may have on that context. Therefore, to characterize a specific context of a study area, it needs to evaluate the interactions between temporal, geographical, social, financial, political, and resource or livelihood capital factors. Climate change effects will modify the biophysical features of the context and influence the interplay between multiple aspects that regulate the dynamics of climate vulnerability (O'Brien, 2007; Thornton, 2014). While it is needed to realize how to identify a context, this is also needed to fix what context must be recognized for develop adaptation policies at various levels (e.g., nationwide, sub-national, or local) (Leichenko, 2014; Erdiaw-Kwasie et al., 2019). In our study, we follow the context-specific approach (Figure 3). Context identification is a great tool to specify and characterization of the context. In our study, after the context is identified, we specify the livelihoods exposure to the climatic vulnerability on context and consequence basis. This phase involves determining the sensitivity of livelihood activities while considering the accessibility and usage of various capital resources for developing and spreading livelihood strategies. There are some steps to accessing adaptive capacity which include government, NGOs institutional planning for fixing the virtue and connectivity to capital assets. For the LVI framework in the study, we identified 8 major components comprising 41 sub-components under the 5 livelihoods capitals: human, natural social, physical, and financial. These consists of food, water, health, socio-demographic profile, livelihood strategies, social network, natural disasters, and climatic variability. This context-specific LVI technique adopted will investigate the actual circumstances of 
216 livelihood vulnerability. The ultimate phase of the approach is an evaluation of adaptation

217 plans to reduce context-specific vulnerability, and prevent unfavorable outcomes.
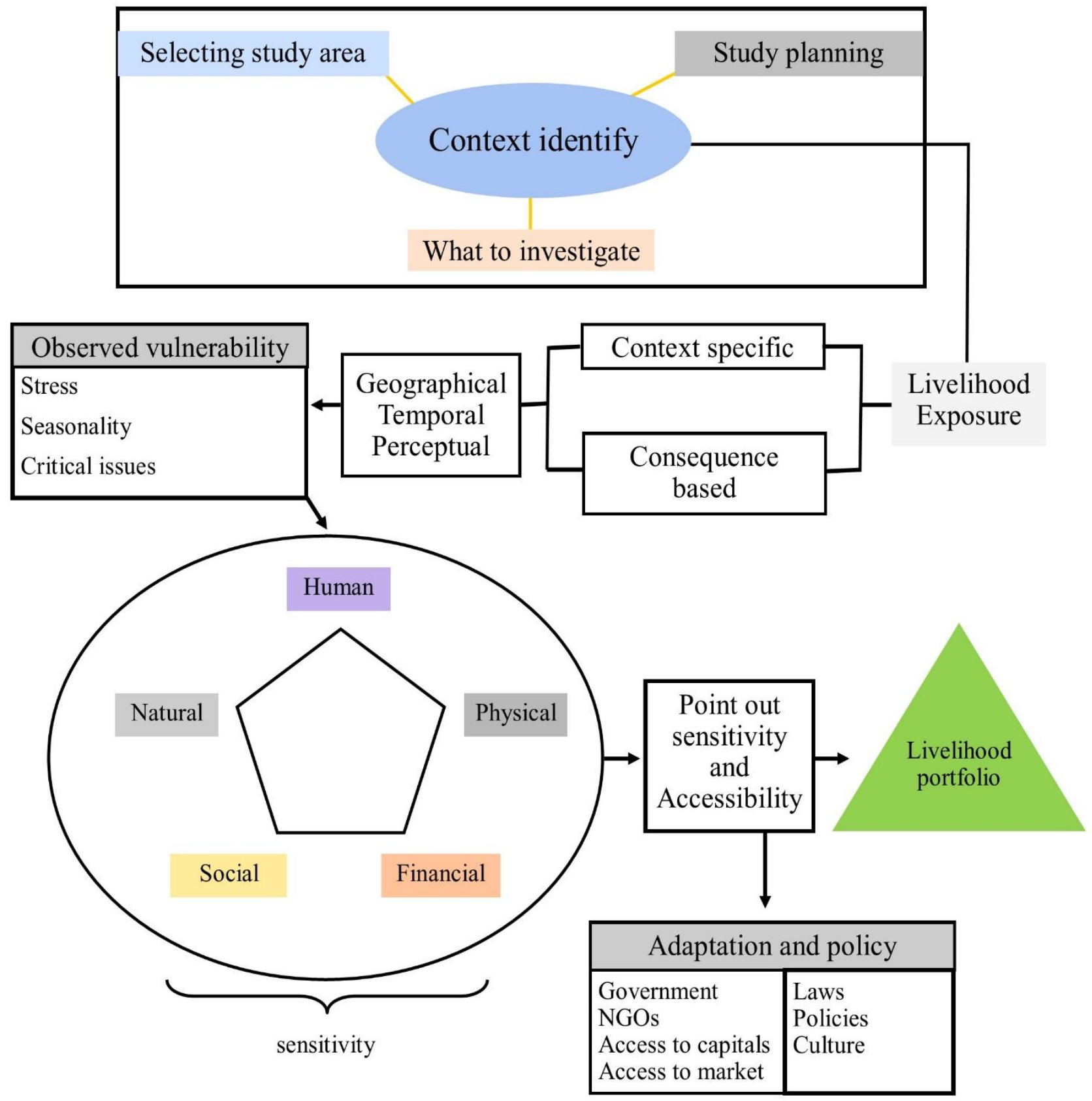

Fig. 3. A context-specific framework approach for livelihood vulnerability

\subsection{Vulnerability analysis}

222 Vulnerability refers to the status of a personal or group to stresses caused by alterations in

223 socio-economic and environmental factors that disrupt livelihoods (Adger, 1999). 
Vulnerability estimation reveals the communal systems and materials result within the framework and recognized the susceptible people and sensitive factors to climatic hazards (Adger, 2006; Ford et al., 2010; Tavares et al., 2015). Vulnerability is determined by the function of three primary dimensions, which are sensitivity, exposure, and adaptive capacity (IPCC, 2007) by the following Eq. (2)

$$
\text { Vulnerability }=\mathrm{f}(\text { Exposure, } \text { sensitivity, adaptive capacity })
$$

In general, vulnerability is a positive function to sensitivity and exposure of the system and a negative function to adaptive capability (Ford et al., 2010; Ford and Smit, 2004; Alam, 2017). Community views of social identity influence outlining climate risk opinion and resulting adaptive capacity (Frank et al., 2011). For this study, we used LVI (Alam, 2017; Hahn et al., 2009; Alam et al., 2017) and CVI (Pandey and Jha, 2012; Alam, 2016; Alam, 2017) to measuring livelihood vulnerability of char land communities and evaluate the comparative degree of the major participating parameters under the comprehensive IPCC framework.

The IPCC livelihood framework approach measures vulnerability using three key functions: sensitivity, exposure, and adaptive capacity. In the study, we utilized a compound index-basis LVI with all major assets of households which including human, social, physical, financial and natural of a Sustainable Livelihood Framework (SLF), which provides a superior assimilation with adaptive capacity and sensitivity. Numbers of scholars have utilized this similar technique (Alam, 2016; Alam et al., 2017; Sarker et al., 2019; Gerlitz et al., 2017; Orencio et al., 2013). The LVI method attentions on assessing the strong suit of present livelihood status, health, food, and water reserve features, as well as households ability to modify these approaches in reply to exposures that are related with climate change (Hahn et al., 2009). The weighted balanced and comprehensive strategy based on LVI and CVI was used, with local and traditional knowledge factored into the indicator selection. In our study, LVI comprises eight major components, comprising livelihood strategies, social network, 
socio-demographic profile, accessibility to water, food, and health, and the negative effects

250

251

252

253

254

255

256

257

258

259

260

261

262

263

264

265

266

$267 \quad M_{d}=\frac{\sum_{i=1}^{n} \text { index }_{d^{i}}}{n}$

Where, $M_{d}=$ one of the major components for the study site, index $_{S_{d^{i}}}=$ subcomponents and $n=$ numbers of sub-components of each major component.

271 When each values of the eight major components for the study area were computed, they 272 were then averaged by Eq. 5 to get the study area LVI. 
$273 \quad L V I_{d}=\frac{\sum_{i=1}^{8} w_{M i} M_{d i}}{\sum_{i=1}^{8} w_{M i}}$

275 Which can also be expressed as-

$L V I_{d}=\frac{w_{S D P} S D P_{d}+w_{L S} L S_{d}+w_{S N} S N_{d}+w_{H} H_{d}+w_{F} F_{d}+w_{W} W_{d}+w_{N D} N D_{d}+w_{C V} C V_{d}}{w_{S D P}+w_{L S}+w_{S N}+w_{H}+w_{F}+w_{W}+w_{N D}+w_{C V}}$

Where, $L V I_{d}=$ Livelihood vulnerability of the study site $d$, that equals the eight major components weighted average. Each weights of the major components, $w_{m i}$, are obtained by the numbers of sub-components which constitute each major component. The weights were involved so that each sub-components participated equally in the overall LVI.

282 The exposure (Exp) index contained climate variability (CV) and natural disasters (ND) and was computed using Eq. 7.

284

$\operatorname{Exp}=\frac{W_{\exp 1} N D+W_{\exp 2} C V}{W_{\exp 1}+W_{\exp 2}}$

Where, $W_{\exp 1}$ and $W_{\exp 2}$ expressed the weight of natural disasters and climate vulnerability correspondingly. calculated using Eq.8.

$290 \quad$ Sen $=\frac{W_{\operatorname{sen} 1} H+W_{\text {sen } 2} F+W_{\text {sen } 3} W}{W_{\exp 1}+W_{\exp 2}+W_{\exp 3}}$

292 Where, $W_{\exp 1}, W_{\exp 2}$ and $W_{\exp 3}$ were expressed the weights of three major components 293 health, food, and water correspondingly. The adaptive capacity (AdaCap) index was computed using following Eq. 9. 
297 Where, $W_{a d 1}, W_{a d 2}$ and $W_{a d 3}$ were expressed the weights of three major components socio298 demographic profile, livelihood strategies, and social networks correspondingly.

299 The index value of the IPCC three-dimension functions sensitivity, exposure, and adaptive 300 capacity were applied to calculate the weighted average of the Climate Vulnerability Index (CVI) as follows:

302

$$
C V I=1-\left|\left\{\frac{N 1 \text { Exp-N2 Ada.cap }}{(N 1+N 2)}\right\}\right| *\left\{\frac{1}{\operatorname{Sen}}\right\}
$$

Where, $N_{i}=$ Numbers of major components in the $i^{t h}$ vulnerability dimension. The value of each dimension varied to a minimum of 0 and a maximum of 1 .

\subsection{IPCC Framework Approach}

The IPCC framework combines the eight major components into three dimensions: sensitivity, exposure, and adaptive capacity. This three participating factors are integrated using Eq. 11.

$$
L V I-I P C C_{d}=(\operatorname{Exp}-A d a \cdot \operatorname{cap}) * \operatorname{Sen}
$$

Where, $L V I-I P C C_{d}=\mathrm{LVI}$ for the community, $d$, denotes the IPCC vulnerability framework.

LVI-IPCC index value ranged to -1 (least vulnerable) and the maximum to 1 (most vulnerable).

The selection of meaningful and robust parameters particular to regional communities is a key issue connected with vulnerability analysis (Adger, 2006; Alam, 2016; Alam et al., 2017; Etwire et al., 2013; Salvati and Carlucci, 2014). However, this limitation is overcome by an exhaustive literature study, firsthand observations, and expert views to get representative and 
319 complete results. The adopted approach may be used to estimate and compare the 320 susceptibility of other rural populations because of the method's flexibility, which allows for

321 adjustments in indicators based on the conditions of a particular state of an area, sector, or

322 community.

Table 1.

Livelihood Vulnerability Index (LVI) components and indicators developed for this study (HHs = households; NGOs = nongovernmental organizations)

\begin{tabular}{|c|c|c|c|c|c|}
\hline & Major & Sub-components or indicator & units & Score/values & Sources \\
\hline \multirow{18}{*}{$\begin{array}{l}\text { Adaptive } \\
\text { capacity }\end{array}$} & Socio- & Dependency ratio & Ratio & If $1: 3$, then & DHS, 2006; Sadekin, \\
\hline & demographic & & & score $=1$, if & 2018; Madhuri., 2014; \\
\hline & profile & & & more $=0$ & Alam, 2017 \\
\hline & & Percent of HHs were the head of the & Percentage & Yes $=1$, No & Hahn et al., 2009; \\
\hline & & HH has not joined school & & $=0$ & Bhuiyan et al., 2017; \\
\hline & & & & & Alam, 2017 \\
\hline & & Average number of family members & count & & Hahn et al., 2009; \\
\hline & & in the HHs & & & Alam, 2017 \\
\hline & Livelihood & Percent of households dependent only & Percentage & Yes $=1$, No & Madhuri., 2014; Alam \\
\hline & strategy & on agriculture as a main income & & $=0$ & et al., 2017; Shah et al., \\
\hline & & source & & & 2013 \\
\hline & & Percent of the HHs taking traditional & Percentage & Yes $=1$, No & Developed for this \\
\hline & & control measures to reduce the & & $=0$ & study \\
\hline & & adverse impacts? & & & \\
\hline & & Percent of HHs have saving account & Percentage & Yes $=1$, No & Developed for this \\
\hline & & & & $=0$ & study \\
\hline & & Percent of HHs have rent out farming & Percentage & Yes $=1$, No & Developed for this \\
\hline & & land & & $=0$ & study \\
\hline
\end{tabular}


Percent of HHs who don't attempt homestead gardening

Percent of HHs that has no farming approaches to survive with erosion

Percent of HHs that have no place for Percentage Yes = 1, No Dapar., 2016 relocation if erosion or disaster occur Percent of HHs who have burden of loan

Social network Percent of HHs who have not gone to Percentage their local government for help in the previous 12 months. $=0$

Percentage $\quad$ Yes $=1$, No Dapar., 2016 $=0$ $=0$ $=0$ 2018

$=0$
Percentage $\quad$ Yes $=1$, No Alam et al., 2017

Yes $=1$, No DHS, 2006; Sadekin,

Yes = 1, No Sadekin, 2018; Madhuri., 2014; WHO/RBM (2003); Shah et al., 2013

Percent of HHs received help from Percentage $\quad$ Yes $=1$, No Jakariya et al., 2020; relatives, neighbors $=0$ Alam, 2017

Percent of $\mathrm{HH}$ received government

Percentage Yes = 1, No Azam, 2019; Alam, and organizational support $=0$ 2017

Percent of household getting credit

Percentage $\quad$ Yes $=1$, No Azam, 2019; Bhuiyan facilities $=0$ et al., 2017

Percent of HHs involved in non-farm Percentage Yes=1, No Alam, 2017; Panthi, et activities? $=0$ al., 2016

Percent of HHs involved in

Percentage $\quad$ Yes $=1$, No Alam et al., 2017;

cooperative society or any $=0$ Hahn et al., 2009

organization?

Percent of HHs getting any training from government organizations?

Percentage

Yes $=1$, No $=0$

$=0 \quad$ study

Percent of HHs getting any training Percentage from a non-government organization?
Yes $=1$, No Developed for this $=0 \quad$ study 
Percent of HHs getting any

information on new technology or

varieties from agri. Extension officer?

Sensitivity Health

Percent of HHs with experience any Percentage

waterborne disease

Percentage $\quad$ Yes $=1$, No Alam et al., 2017

$=0$

Percent of HHs those family members Percentage

suffering from chronic disease

$=0$

Percent of HHs who don't attend a

Percentage

local doctor through illness

$=0$ 2014; Fraser, 2011

Percent of HHs receiving treatment in Percentage Yes $=1$, No Madhuri., 2014;

government hospitals

$=0$

Madhav, 2010

Percent of HHs in which a family

Percentage

member skipped work due to disease

$=0$

2018; Ahsan, 2014

in the previous two weeks

Percent of HHs having sanitary

latrines

Percentage $\quad$ Yes $=1$, No Alam et al., 2017;

$=0$

Gbetibouo, 2010;

Preston, 2011

Food Average number of months HHs work Count

to find food

Bank.,1998; Hahn et

al., 2009

Percent of HHs who don't save crops Percentage Yes = 1, No Hahn et al., 2009;

Percent of HHs missing their farming Percentage

land

Percent of HHs facing food insecurity Percentage and malnutrition are increasing in the
$=0$

Sadekin, 2018

$=0$

Yes $=1$, No Alam, 2017

Yes $=1$, No Developed for the

$=0$

purposes of this study 
previous 10 years?

Water

Percent of HHs reporting water

Percentage $\quad$ Yes $=1$, No Sujakhu, 2019; Alam .

conflicts

$=0$ 2017

Percent of HHs using unsafe drinking Percentage Yes =1, No Alam, et al., 2017;

water (pond, river, water hole,

$=0$

Azam, 2019.

arsenic-contaminated water)

Percent of HHs receiving water from Percentage Yes =1, No Alam, 2016; Jacobson,

a distant (more than $0.5 \mathrm{~km}$ ) water

$=0$ 2018

source (tube well)

Exposure Natural Percent of households affected by

Percentage $\quad$ Yes $=1$, No Bhuiyan et al., 2017

disasters floods and riverbank erosion during

$=0$

Dapar., 2016

last 10 years?

Percent of agricultural land affected

Count

Yes = 1, No Dapar., 2016; Alam,

by erosion

$=0$ 2016

Average number of other natural

Percentage

Bhuiyan et al., 2017

calamities during previous 10 years

Percent of HHs faced movement in

Percentage Yes $=1$, No Alam, 2017; Bhuiyan

previous 10 years

$=0 \quad$ et al., 2017

Percent of HHs loss livestock due to

Percentage

Yes = 1, No Alam, 2017; Bhuiyan

natural disaster during previous 10

$=0$

et al., 2017

years?

Climatic Facing progressively increasing

Percentage Yes $=1$, No Shah et al., 2018 ;

variability temperature from previous 10 years

$=0$

Hahn et al., 2009;

Alam et al., 2017

Facing gradully decreasing rainfall

Percentage Yes $=1$, No Developed for the

from previous 10 years

$=0$

purposes of this study

Facing progressively growing

Percentage Yes $=1$, No Alam, 2017; Alam et 


\section{Results and discussion}

In this segment, the outcomes of LVI, and CVI are summarized from the survey. The LVI outcome values are shown in Table 2.

Table 2 outlines the factors that contribute toward vulnerability for each region. The differences in LVI and CVI values between the study area show that the vulnerability of Char Jotindro-Narayan and Kulaghat char households differ overall and regarding the specific components and sub-components mentioned below.

\subsection{Livelihood vulnerability index}

The value of LVI in Kulaghat char (0.402) was more than Char Jotindr-Naran under Lalmonirhat Sadar and Phulbari Upazila, respectively (Table 2). These LVI values denote that the households of Kulaghat char and Char Jotindr-Naran had a distinct level of vulnerability. Kulaghat char households were faced with more problems than Char JotindrNaran, owing to lack of accessibility to financial resources, and health care and educational opportunities, as well as intense exposure to climatic vulnerability (Table 2). The study shows that the two household groups had similar socio-demographic profile, natural disasters, but lot of differences in several sub-component such as social network, livelihood strategies, food, and climatic variability. The dependency ratio of household head is higher in Char Jotindr-Naran than in Kulaghat char. The value of livelihoods strategy is lower in Char Jotindr-Naran (0.22525) while higher in Kulaghat char (0.3275) (Table 2). The social network indexing value varied slightly among the study areas. The social network and food index values were higher in Char Jotindro-Narayan with the value of $(0.350111)$ and $(0.588)$ 
346 findings are explained more in detail below.

\section{Table 2.}

Indexed value of the major components and sub-components consist of livelihood vulnerability index (where HHs = households).

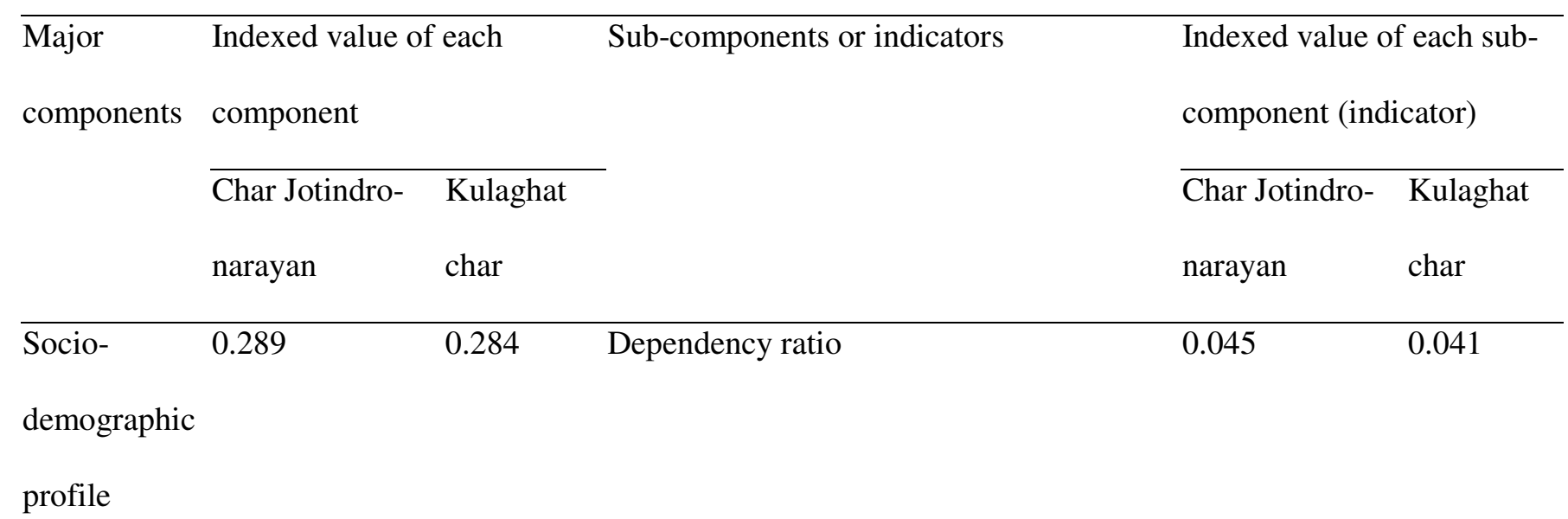

Percent of HHs where the head of the HH 0.53

has not attended school

Average number of family members in the 0.292

HHs

Livelihood $\quad 0.225$

0.327

Percent of households dependent only on $\quad 0.265$

strategy

agriculture as a main income source

Percent of the HHs taking traditional

0.273

control measures to reduce the adverse

impacts?

Percent of HHs have saving account

Percent of HHs have rent out farming land 0.136

Percent of HHs who don't attempt

0.129

homestead gardening

Percent of HHs that has no farming

0.553

0.689

approaches to survive with erosion 
Percent of HHs that have no place for

relocation if erosion or disaster occur

Percent of HHs who have burden of loan $\quad 0.25$

Social

0.350111

0.315

Percent of HHs who have not gone to their 0.75

network

local government for help in the previous

12 months

Percent of HHs received help from

0.553

0.538

relatives, neighbors

Percent of $\mathrm{HH}$ received government and $\quad 0.379$

organizational support

Percent of household getting credit

0.371

0.212

facilities

Percent of HHs involved in non-farm $\quad 0.386$

activities?

Percent of HHs involved in cooperative

society or any organization?

Percent of HHs getting any training from 0.159

government organizations?

Percent of HHs getting any training from a 0.22

non-government organization?

Percent of HHs getting any information on 0.174

new technology or varieties from agri.

Extension officer?

Health $\quad 0.315$

Percent of HHs with experience any

waterborne disease

Percent of HHs those family members

suffering from chronic disease 
Percent of HHs who don't attend a local 0.038

doctor through illness

Percent of HHs receiving treatment in $\quad 0.697$

government hospitals

Percent of HHs in which a family member 0.174

skipped work due to disease in the

previous two weeks

Percent of HHs having sanitary latrines $\quad 0.265$

Food

0.588

0.512

Average number of months HHs work to 0.745

0.799

find food

Percent of HHs who don't save crops $\quad 0.258$

Percent of HHs missing their farming land 0.879

Percent of HHs facing food insecurity and 0.47

0.402

malnutrition are increasing in the previous

10 years?

Water

0.020

0.04

Percent of HHs reporting water conflicts $\quad 0.023$

Percent of HHs using unsafe drinking $\quad 0.038$

water (pond, river, water hole, arsenic-

contaminated water)

Percent of HHs receiving water from a 0

0.03

distant (more than $0.5 \mathrm{~km}$ ) water source

(tube well)

Natural

0.781

0.781

Percent of households affected by floods 0.962

disasters

and riverbank erosion during last 10 years?

Percent of agricultural land affected by $\quad 0.955$

erosion

Average number of other natural 
calamities during previous 10 years

Percent of HHs faced movement in

previous 10 years

Percent of HHs loss livestock due to

0.553

0.508

natural disaster during previous 10 years?

Climatic $\quad 0.671$

0.717

Facing progressively increasing

0.932

0.955

variability

temperature from previous 10 years

Facing gradully decreasing rainfall from $\quad 0.689$

previous 10 years

Facing progressively growing riverbank $\quad 0.394$

erosion from previous 10 year

Overall livelihood vulnerability index:

Char Jotindro-narayan: 0.391, Kulaghat char: 0.402

Source: Field Survey, 2021

347 The outcomes of the major components aare displayed in the spider diagram (Fig. 4). The

348 climatic variability value in Char Jotindro-Narayan is lower with the value of $(0.671)$, while

349 in Kulaghat char, it was (0.717). The value of natural disasters in both char communities was

350 similar because of their low-lying geography and extreme vulnerability for flood disasters with enormous riverbank erosion. 


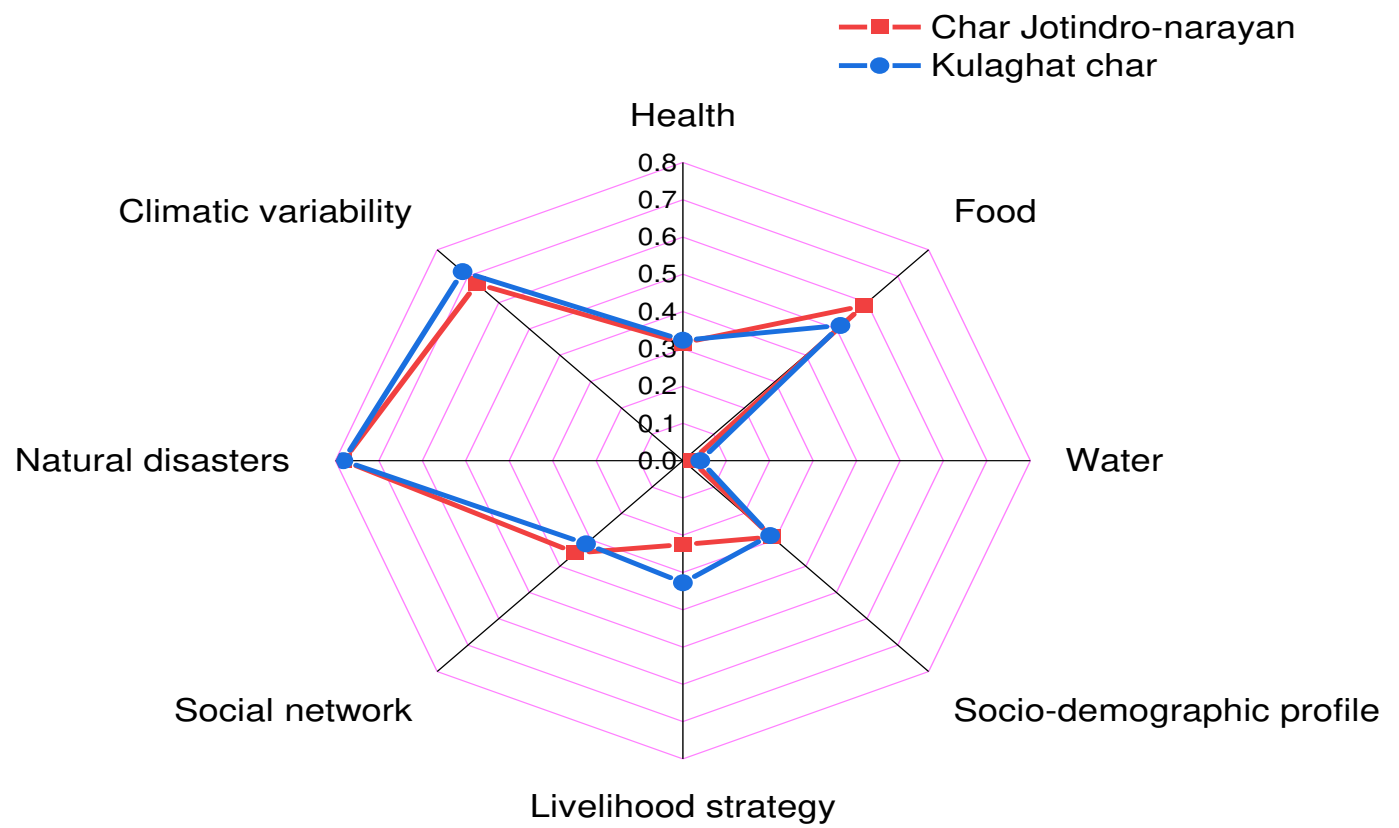

Fig. 4. The spider diagram of major components of LVI for both study areas.

\subsection{Climate vulnerability index}

The outcomes of climate vulnerability index (CVI) for the study area is presented in Table 3.

The CVI values denote there was almost no distinction between the two char communities, but the values in Kulaghat char (0.639) are slightly higher than Char Jotindro-Narayan (0.633).

Figure 5 reveals the vulnerability triangle, this exhibits the score participating elements for the sensitivity, exposure, and adaptive capacity. The result shows that the households of Char Jotindro-Narayan have higher sensitivity in the basis of access to food, health, and water with a value of (0.331), while it shows lower in Kulaghat char with the value of (0.316). The study reveals that the char land communities of Kulaghat char are slightly exposed than Char Jotindro-Narayan. However, both study regions are equally affected by flood and riverbank erosion per year and are most vulnerable.

Table 3. 
Indexed dimensions of climate vulnerability of Char Jotendro-narayan and Kulaghat char

\begin{tabular}{lcc}
\hline Contributing elements to vulnerability & Char Jotindro- & Kulaghat \\
& narayan & char \\
\hline Adaptive capacity (socio-demographic, livelihood strategies and social & 0.291 & 0.315 \\
network) & & 0.316 \\
Sensitivity (Health, food, water) & 0.331 & 0.757 \\
Exposure (Natural disasters and climatic variability) & 0.74 & 0.639 \\
Climate Vulnerability Index (CVI) & 0.633 & 0.139 \\
LVI-IPCC & 0.148 &
\end{tabular}

Source: Field Survey, 2021

368 LVI-IPCC vulnerability index outcomes represent that the Char Jotindro-Narayan households are most vulnerable than the char Kulaghat households with the index value of $(0.148)$ and (0.139) correspondingly (Table 3).

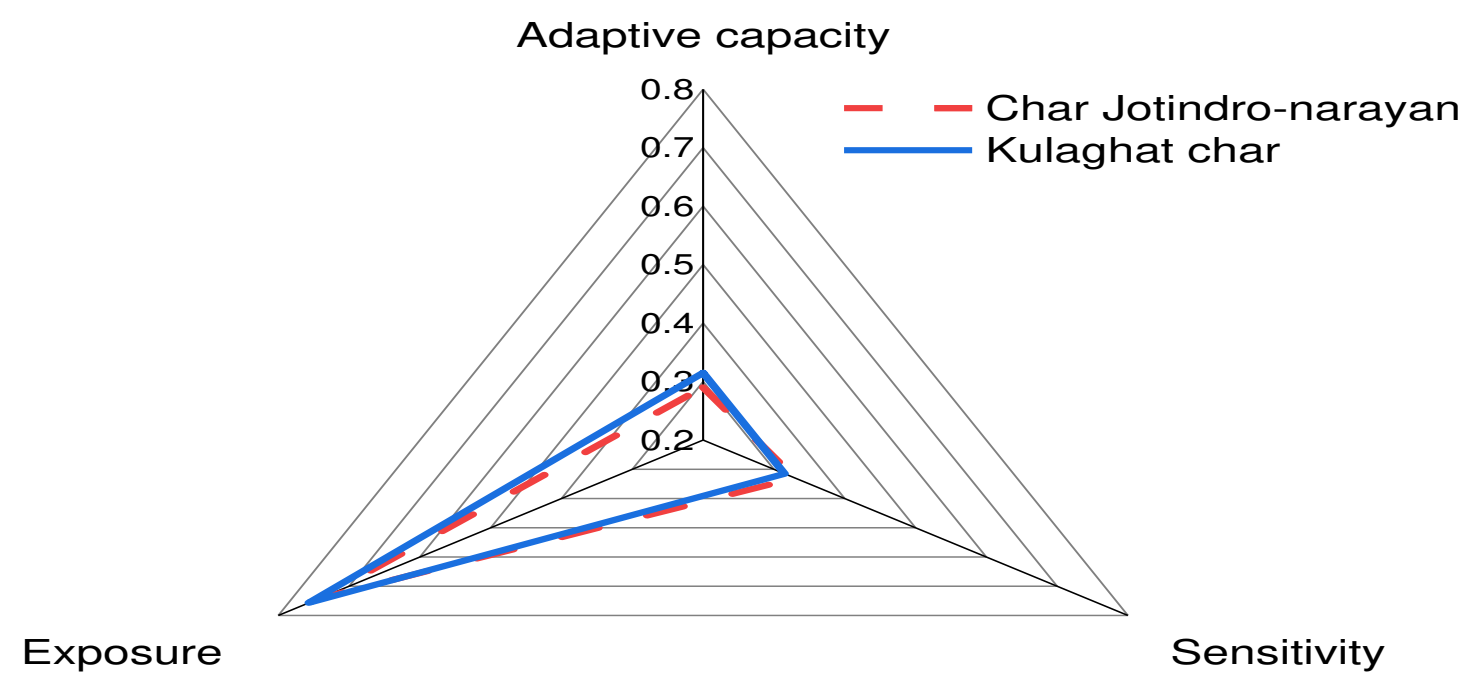

Fig. 5. The vulnerability triangle diagram of the dimensions of the Climate Vulnerability Index.

Source: Field Survey, 2021 


\subsection{Livelihood vulnerability}

377 The outcomes show that the livelihood vulnerability condition in Kulaghat char was higher than the Char Jotindro-Narayan households. The most significant contributing components values of livelihood strategy (0.327), health (0.323), water (0.04), and climate variability (0.717 were higher in Kulaghat char than Char Jotindro-Narayan, which were $0.225 ; 0.315$; 0.020 , and 0.671 respectively (Table 2 ).

The livelihood strategy components contribution in Kulaghat char represents that these community households mainly depend on farming for their main earnings and food safety. Riverbank erosion and floods regularly damage their agricultural land, crops, etc. where households have no farming strategies to cope with these situations, and the few households practiced homestead gardening to fight against high natural hazards and climatic variability. The agriculture-based livelihoods can leave households in a more vulnerable position if they lack the option to diversify their livelihood plan (Alam et al., 2017; Alam, 2016; Mirza, 2003). In the Kulaghat char region, the water component had an even more impact on vulnerability. In this region households were used unsafe drinking water from the pond, river, water hole/tube wells, and majority of these have been reported to be infected by arsenic. In conversations, this was noticeable that households were conscious of the hazards of imbibing arsenic-contaminated water, then alternatives are frequently inaccessible; water conflict is also a problem among communities, with disputes frequently arising over water accessibility and property rights, such as ownership. The finding shows that households of the char Kulaghat are more vulnerable on health-related issues that impact both people and cattle. People in rural locations drive a greater distance for attend health-care facilities, and availability to veterinary competence is also inadequate due to poor communication systems. The findings revealed that the number of waterborne diseases and chronically ill people in 
regularly denied normal government care owing to limited accessibility. The study found that the Kulaghat char household's perceived temperature and rainfall fluctuation rates over the last 10 years are more than the Char Jotindro-Narayan.

The results show that both char land households are vulnerable, but Char Jotindro-Narayan households are more vulnerable than Kulaghat char due to its residents living far away from the mainland. This is most likely owing to services given by government and nongovernmental groups, improved social networks and communication, educational amenities, and comfortable relocation through natural catastrophes (Alam et al., 2017; Sarker et al., 2019). Char Jotindro-Narayan households generally have a poorer range of education and a greater prevalence of malnutrition. Traditional views (especially surrounding local remedies for health difficulties) and a lack of education generate community obstacles that influence family vulnerability and adaptive capability (Alam et al., 2016; Jones and Boyd, 2011).

Riverbank erosion is the general problem in char regions, and these study locations experience it frequently. The degree of riverbank erosion within Char Jotindro-Narayan is larger than in Kulaghat char. The overall LVI and CVI index was high index value in Kulaghat char. The Char Jotindro-Narayan households are mainly struggling higher than Kulaghat char households with natural disasters, social networking, and food security due to the proximity of the river Dharla. Similar outcomes are obtained in a few research (Alam, 2016; Sarker et al., 2019). The CVI (Table 3) shows vulnerability to climate-driven hazards by providing index values of sensitivity, adaptive capacity, and exposure to climate change. The results in Table 3 show that by IPCC-LVI index, Char Jotindro-Narayan is the highest vulnerable area with less adaptive capability than households of Kulaghat char. Char Jotindro-Narayan households has lower income sources, a higher reliance on agriculture, a higher dependence ratio, and a better education level.

\subsection{Policy implications and lesion learning}


426 A context-specific intervention program for char communities is required. To promote 427 societal resilience, reduce the sensitivity of habitat conditions, and increase individual stability to solve livelihood issues, particularly for female-headed households. The participation of different GO and NGO safety net programs is insufficient in the areas; it should be greatly enlarged. Moreover, on a long-term basis, the development of a communication network, transportation system, basic services accessibility, and market facilities for other livelihoods plans is also crucial. Access to financing for poor farmers should be promoted to help improve their access to resources and technology, which is critical for their adaptability. Although the char households' livelihood depends mainly on agriculture, agricultural institutions should be encouraged to generate new crop varieties and promote technology-transfer mechanisms. This would improve the resilience of vulnerable households of the char land communities in Bangladesh.

The intensity of livelihoods vulnerability of a community is mainly depending on their assets and natural resources. The context-specific views represent the vulnerability intensity into a distinct scale, which also varies by the term of geographic location, perceptual responses, and temporal/ seasonal stress or critical issues with community livelihoods capitals. In a devolving country like Bangladesh, climate change effects including floods and riverbank erosion are especially affected the (bar land) char land communities which damages natural resources and their saving that resulting making more vulnerable. A large number of 445 farmland and crops are damaged due to floods and riverbank erosion that reducing the 446 financial growth of the community. The study reveals that, peoples in the community who are aware and adoption different measure to stand against the floods, riverbank erosion, critical issues or other stresses they are least vulnerable. Therefore, to decreasing the sensitivity of livelihoods vulnerability in such char communities policymakers could amplify these above 
offers of training and additional services, especially for basic needs, information, and communication technologies.

\section{Conclusion}

453

454

Geologically, Bangladesh is the most natural disaster susceptible country because of its lowlying landscape and climate change. Char regions are separated from the interior land and found across the country's enormous river-delta system. Using survey data, this study investigated the extent of adaptive capacity and vulnerability of the char households of Bangladesh applying vulnerability framework. The char areas are commonly impacted by environmental hazards, including flood, riverbank erosion, heatwave, and drought, which greatly loses their livelihood assets. The outcomes represent that the study regions are the greatest vulnerable to climate change and natural disaster, where sensitivity and exposure level exceed adaptive capacity. The study reveals that the food, social network components, natural disasters, and climatic variability are the major drivers increasing both char land communities' vulnerability. The LVI and CVI outcomes represent that both char communities are vulnerable to natural disasters and climatic variability. However, disparities in subcomponent values among char communities suggest that climate change vulnerability varies even within units of individuals undertaking in same livelihood activities. A long-term sustainable development strategy that includes road construction, tree plantation, employment opportunities, and capacity building will be beneficial in building resilience among households in such vulnerable regions in Bangladesh.

\section{Acknowledgement}

The authors extend their appreciation to the Deanship of Scientific Research at King Khalid University for funding this work through general program under grant number (GRP /132/42).

\section{Conflict of interest}

None

\section{References}


Adger, W.N., 1999. Social vulnerability to climate change and extremes in coastal Vietnam. World Dev. 27, 249-269.

Adger, W.N., Vincent, K., 2005. Uncertainty in adaptive capacity. Comptes Rendus Geosci. 337, 399-410.

Adger, W.N., Vulnerability. 2006. Glob. Environ. Chang. 16, 268-281.

Ahmed, I., Alam, M., Jimmy, A., Fatema, K., Islam, M., Ahsan, G., Khan, N., 2019. Climate change induced migration: empirical evidences from the southwest coastal region of Bangladesh. Int. J. Environ. Sustain Dev. 3 (4), 116-126.

Ahsan, M.N., Warner, J., 2014. The socioeconomic vulnerability index: A pragmatic approach for assessing climate change led risks-A case study in the south-western coastal Bangladesh. Int. J. Disaster Risk Reduct. 8, 32-49.

Alam, G.M.M., 2016. An assessment of the livelihood vulnerability of the riverbank erosion hazard and its impact on food security for rural households in Bangladesh. In: PhD Thesis. School of Commerce, University of Southern Queensland, Australia.

Alam, G.M.M., 2017. Livelihood Cycle and Vulnerability of Rural Households to Climate Change and Hazards in Bangladesh. Environ. Manage. 59, 777-791.

Alam, G.M.M., Alam, K., \& Shahbaz, M., 2016. Influence of institutional access and social capital on adaptation choices: Empirical evidence from vulnerable rural households in Bangladesh. Ecol Econ, 130: 243-251.

Alam, G.M.M., Alam, K., \& Shahbaz, M., Sarker, M.N.I., 2020. Hazards, food insecurity and human displacement in rural riverine Bangladesh: Implications for policy. Int J. of Dis. Ris. Red., 43: 101364.

Alam, G.M.M., Alam, K., Mushtaq, S., 2018. Drivers of Food Security of Vulnerable Rural Households in Bangladesh: Implications for Policy and Development. South Asia Econ. J. 19, 43-63. 
501

502

503

504

505

506

507

508

509

510

511

512

513

514

515

516

517

518

519

520

521

522

523

Alam, G.M.M., Alam, K., Mushtaq, S., Clarke, M.L., 2017. Vulnerability to climatic change in riparian char and river-bank households in Bangladesh: Implication for policy, livelihoods and social development. Ecol. Indic. 72, 23-32.

Ayanlade, A., Radeny, M., \& Akin-Onigbinde, A. I., 2018. Climate variability/change and attitude to adaptation technologies: a pilot study among selected rural farmers ' communities in Nigeria. GeoJournal. 83(2), 319-331.

Azad, A.K., Hossain, K.M., \& Nasreen, M., 2013. Flood induced vulnerabilities and problems encountered by women in northern Bangladesh. International Journal of Disaster Risk Science. 4(4), 190-199.

Bangladesh Bureau of Statistics (BBS), 2011. Bangladesh Population Census 2011, Statistics Division, Ministry of Planning, Government of the People's Republic of Bangladesh, Dhaka.

Bangladesh Bureau of Statistics (BBS), 2014. Statistical Pocketbook; BBS: Dhaka, Bangladesh.

Barrett, A., Hannan, M., Alam, Z., Pritchard, M., 2014. Impact of the Chars Livelihoods Programme on the Disaster Resilience of Chars Communities. Available online: https://www.gdnonline.org/resources/impact\%20of\%20clp\%20on\%20the $\% 20$ disaster $\% 2$ Oresilience\%20of\%20char\%20communities\%20[final].pdf (accessed on 15 March 2019).

Bevacqua, A., Yu, D., Zhang, Y., 2018. Coastal vulnerability: Evolving concepts in understanding vulnerable people and places. Environ. Sci. Policy. 82, 19-29.

CARE-Bangladesh and DFID-B., 2002. The Findings of the Northwest Rural Livelihoods Baseline; CARE-Bangladesh and DFID-B: Dhaka, Bangladesh. 
Center for Environmental and Geographic Information Services (CEGIS), 2012. Prediction of River Bank Erosion Along the Jamuna, the Ganges the Padma and the Lower Meghna Rivers in 2012; Centre for Environment and Geographic Information Services: Dhaka, Bangladesh.

Christensen, J.H., Hewitson, B., et al., 2007. Regional climate projections. In: Solomon, S. (Ed.), Climate Change 2007: The Physical Science Basis. Contribution of Working Group I to the Fourth Assessment Report of the Intergovernmental Panel on Climate Change. Cambridge University Press, Cambridge.

CLP, 2010. Impact of earlier recruitment into the CLP on mother and child nutritional status among chars dwellers. In: Chars Livelihoods Program. Rural Development Academy Campus, Bogra, Bangladesh.

Cochran, W. G., W, J., Sons, 1977. Sampling techniques.

EGIS, 2000. Riverine Chars in Bangladesh-environmental dynamics and management issues. In Environment and GIS Support Project for Water Sector Planning (EGIS); University Press Limited: Dhaka, Bangladesh.

Erdiaw-Kwasie, M. O., Abunyewah, M., \& Yamoah, O., 2019. 'After the disaster comes destination thoughts': A review and conceptualization of consolidative disaster adaptive capacity model. International Journal of Disaster Risk Reduction, 35, 101098.

Eriksen, S.H., Kelly, P.M., 2007. Developing credible vulnerability indicators for climate adaptation policy assessment. Mitig. Adapt. Strateg. Glob. Chang. 12, 495-524.

Etwire, P.M., Al-Hassan, R.M., Kuwornu, J.K.M., Osei-Owusu, Y., 2013. Application of livelihood vulnerability index in assessing vulnerability to climate change and variability in Northern Ghana. J. Environ. Earth Sci. 3, 157-170.

Folke, C., 2006. Resilience: The emergence of a perspective for social-ecological systems analyses. Glob. Environ. Chang. 16, 253-267. 
Ford, J.D., Keskitalo, E., Smith, T., Pearce, T., Berrang, L., Duerden, F., Smit, B., 2010.Case study and analogue methodologies in climate change vulnerability research. Wiley Interdiscip. Rev. Clim. Change. 1, 374-392.

Ford, J.D., Smit, B., 2004. A framework for assessing the vulnerability of communities in the Canadian Arctic to risks associated with climate change. Arctic. 57, 389-400.

Frank, E., Eakin, H., Lopez-Carr, D., 2011. Social identity, perception and motivation in adaptation to climate risk in the coffee sector of Chiapas, Mexico. Glob.Environ. Change $21,66-76$.

Gbetibouo, G.A., Ringler, C., Hassan, R., 2010. Vulnerability of the South African farming sector to climate change and variability: An indicator approach. Nat. Resour. Forum. 34, $175-187$.

Gerlitz, J.Y., Macchi, M., Brooks, N., Pandey, R., Banerjee, S., Jha, S.K., 2017. The Multidimensional Livelihood Vulnerability Index-an instrument to measure livelihood vulnerability to change in the Hindu Kush Himalayas. Clim. Dev. 9, 124-140.

GoB (Government of Bangladesh), 2011. The Sixth Five-year Plan, 2011-2015. Ministry of Planning Govt. of the People's Republic of Bangladesh, Dhaka, Bangladesh.

Hahn, M.B., Riederer, A.M., Foster, S.O., 2009. The livelihood vulnerability index: a pragmatic approach to assessing risks from climate variability and change - a case study in Mozambique. Glob. Environ. Change. 19, 74-88.

Huq, S., Ayers, J., 2008. Climate change impacts and responses in Bangladesh. In Briefing Note Prepared for the European Parliament; International Institute for Environment and Development: London, UK; Policy Department Economic and Scientific Policy, DG Internal Policies of the Union: Brussels, Belgium. 
Iffat, M., Mbuya., Nkosinathi., 2016. Water, Sanitation, Hygiene, and Nutrition in Bangladesh: Can Building Toilets Affect Children's Growth? World Bank Study: Washington, DC: World Bank.

Intergovernmental Panel on Climate Change (IPCC), 2014. Climate Change 2014: Impacts, Adaptation and Vulnerability, Fifth Assessment Report. In Intergovernmental Panel on Climate Change; Cambridge University Press: Cambridge, UK.

International Fund for Agricultural Development (IFAD), 2011. How Does International Price Volatility Affect Domestic Economies and Food Security? Office of Knowledge Exchange, Research and Extension, Food and Agriculture Organization of the United Nations (FAO): Rome, Italy.

IPCC, 2007. Climate change 2007: Impacts, adaptation and vulnerability, Fourthassessment report. In: Intergovernmental Panel on Climate Change. Cambridge University Press, Cambridge, UK.

Islam, A.R.M.T., Shen, S., Yang, S., Hu, Z., Chu, R., 2019. Assessing recent impacts of climate change on design water requirement of Boro rice season in Bangladesh. Theoretical and Applied Climatology 135(1):1-17. DOI: 10.1007/s00704-019-02818-8.

Islam, M.R., 2018. Climate Change, Natural Disasters and Socioeconomic Livelihood Vulnerabilities: Migration Decision Among the Char Land People in Bangladesh. Soc. Indic. Res. 136, 575-593.

Islam, M.R., Hossain, D., 2013. Island Char resource mobilization (ICRM): Changes of livelihoods of vulnerable people in Bangladesh. Soc. Indic. Res. 117, 1033-1054.

Islam, S. M. D., 2014. Geoelectrical and hydrogeochemical studies for delineating seawater intrusion in coastal aquifers of Kalapara upazila, Patuakhali, Bangladesh. Unpublished Masters Thesis, Department of Environmental Sciences, Jahangirnagar University, Dhaka. 
Islam, S. M. D., Bhuiyan, M. A. H., 2016. Impact scenarios of shrimp farming in coastal region of Bangladesh: an approach of an ecological model for sustainable management. Aquaculture International. 24(4), 1163-1190. https://doi.org/10.1007/s10499- 016-9978-

Islam, S. M. D., Bhuiyan, M. A. H., 2018. Sundarbans mangrove forest of Bangladesh: causes of degradation and sustainable management options. Environmental Sustainability. 1(2), 113-131. https://doi.org/10.1007/s42398-018-0018-y.

Islam, S.M. D., Uddin, M. J., 2015. Impacts, vulnerability and coping with cyclone hazard in coastal region of Bangladesh: a case study on Kalapara upazila of Patuakhali district. Jahangirnagar University Environmental Bulletin. 4, 11-30.

Jones, L., Boyd, E., 2011. Exploring social barriers to adaptation: insights from western Nepal. Glob. Environ. Change. 21, 1262-1274.

Jurgilevich, A., Räsänen, A., Groundstroem, F., Juhola, S. A., 2017. Systematic review of dynamics in climate risk and vulnerability assessments. Environ. Res. Lett.12, 013002.

Leichenko, R., Silva, J.A., 2014. Climate change and poverty: Vulnerability, impacts, and alleviation strategies. Wiley Interdiscip. Rev. Clim. Chang. 5, 539-556.

Mirza, M., 2003. Climate change and extreme weather events: can developing countries adapt? Clim. Policy. 3, 233-248.

Mondal, M.S.H., Murayama, T., Nishikizawa, S., 2020. Assessing the flood risk of riverine households: A case study from the right bank of the Teesta River, Bangladesh, International Journal of Disaster Risk Reduction, https://doi.org/10.1016/j.ijdrr.2020.101758.

Monwar, M.M., Mustafa, M.G., Khan, N.A., Hossain, M.S., Hossain, M.M., Majumder, M.K., Chowdhury, R.M., Islam, M.A., Chowdhury, M., Alam, M.S., 2018. Indigenous 
adaptation practices for the development of climate resilient ecosystems in the Hail Hoar, Bangladesh. Global Social Welfare. 5(2), 125-136.

623

624

625

626

627

628

629

630

631

632

633

634

635

636

637

638

639

640

641

642

643

Mutton, D., Haque, C.E., 2004. Human Vulnerability, Dislocation and Resettlement: Adaptation Processes of River-bank Erosion-induced Displacees in Bangladesh. Disasters. 28, 41-62.

Nelson, D.R., Adger, W.N., Brown, K., 2007. Adaptation to Environmental Change: Contributions of a ResiliencenFramework. Annu. Rev. Environ. Resour. 32, 395-419.

O’Brien, K., Eriksen, S., Nygaard, L.P., Schjolden, N.E., 2007. Why different interpretations of vulnerability matter in climate change discourses. Clim. Policy. 7, 73-88.

Oo, A.T., Van Huylenbroeck, G., Speelman, S., 2018. Assessment of climate change vulnerability of farm households in Pyapon District, a delta region in Myanmar. Int. J. Disaster Risk Reduct. 28, 10-21.

Orencio, P.M., Fujii, M., 2013. An Index to Determine Vulnerability of Communities in a Coastal Zone: A Case Study of Baler, Aurora, Philippines. Ambio. 42, 61-71.

Pandey, R., Jha, S., 2012. Climate vulnerability index-measure of climate change vulnerability to communities: a case of rural lower Himalaya, India. Mitig.Adapt. Strat. Glob. Change. 17, 487-506.

Panthi, J., Aryal, S., Dahal, P., Bhandari, P., Krakauer, N. Y., Pandey, V.P., 2016. Livelihood vulnerability approach to assessing climate change impacts on mixed agro-livestock smallholders around the Gandaki River basin in Nepal. Regional Environmental Change. 16(4), 1121-1132.

Preston, B.L., Yuen, E.J., Westaway, R.M., 2011. Putting vulnerability to climate change on the map: A review of approaches, benefits, and risks. Sustain. Sci. 6, 177-202. 
Salvati, L., Carlucci, M., 2014. A composite index of sustainable development at the local scale: Italy as a case study. Ecol. Indic. 43, 162-171.

Sarker, M.N.I., Wu, M., Alam, G.M.M., Shouse, R.C., 2019. Livelihood Vulnerability of Riverine-Island Dwellers in the Face of Natural Disasters in Bangladesh. Sustainability $11,1623$.

Sarker, M.N.I., Wu, M., Alam, G.M.M., Shouse, R.C., 2020. Livelihood resilience of riverine island dwellers in the face of natural disasters: Empirical evidence from Bangladesh. Land use policy 95, 104599

Schneider, S.H., 2007. Climate change: impacts, adaptation and vulnerability. In: ParryML, Canziani OF, Palutikof JP, Van der Linden PJ, Hanson CE (eds) Contribution of working Grou-II to the fourth assessment report of the intergovernmental panel on climate change. Cambridge University Press, Cambridge, pp 779-810.

Simotwo, H. K., Mikalitsa, S. M., Wambua, B. N., 2018. Climate change adaptive capacity and smallholder farming in trans-Mara East sub-County, Kenya. Geoenvironmental Disasters. 5(5). https://doi.org/10.1186/s40677-018-0096-2.

Tavares, A.O., Santos, P.P.D., Freire, P., Fortunato, A.B.F., Rilo, A., SA, L., 2015. Flooding hazards in the Tagus estuarine area: the challenge of scale invulnerability assessments. Environ. Sci. Policy. 51, 238-255.

Thompson, P.M., 2000. Bangladesh Char Lands: A Review of Assets and Change. International Centere for Living aquatic Resource management (ICLARM), Dhaka.

Thornton, P.K., Ericksen, P.J., Herrero, M., Challinor, A.J., 2014. Climate variability and vulnerability to climate change: A review. Glob. Chang. Biol. 20, 3313-3328.

Toufique, K. A., Islam, A., 2014. Assessing risks from climate variability and change for disaster-prone zones in Bangladesh. International Journal of Disaster Risk Reduction. $10,236-249$. 
669 UNDP, 2008. Human Development Reports 2007/8. In Fighting Climate Change: Human 670 Solidarity in a Divided World; Human Development Report Office (HDRO), United 671 Nations Development Programme: New York, NY, USA. pp. 1-115.

672 Vignieri, S., 2015. How to adapt to climate change. Science, 349(6248), 599-600. $673 \quad$ https://doi.org/10.1126/science.349.6248.599-f.

674 Zhang, Q., Zhao, X., Tang, H., 2018. Vulnerability of communities to climate change: 675 application of the livelihood vulnerability index to an environmentally sensitive region 676 of China. Climate and Development. https://doi.org/10.1080/17565529.2018.1442808. 